\title{
Learning from community-designed minigrant programs in the Food Dignity project
}

\section{FoodDignity}

\author{
Monica Hargraves * \\ Cornell University
}

Submitted February 23, 2018 / Published online July 18, 2018

Citation: Hargraves, M. (2018). Learning from community-designed minigrant programs in the Food Dignity project. Journal of A griculture, Food Systems, and C ommunity D evelopment, 8(Suppl. 1), 117-146.

https:/ / doi.org/ 10.5304/ jafscd.2018.08A.007

Copyright @ 2018 by the Author. Published by the Lyson Center for Civic Agriculture and Food Systems. Open access under CC BY license.

\begin{abstract}
The Food Dignity project was a five-year (20112016, plus a two-year extension), US\$5 million collaborative action research project funded by the U.S. D epartment of Agriculture's Agriculture and Food Research Initiative, that brought together individuals from four universities and five community organizations. The project goal was to learn from and with these community organizations working to strengthen local food systems and build food justice in their communities. As part of the action research, the partnering community organizations each received US\$30,000 to be distributed in their communities in the form of
\end{abstract}

* Monica Hargraves, Associate Director for Evaluation Partnerships, Cornell O ffice for Research on Evaluation, Cornell University; 35 Thornwood D rive, Suite 200, Room 150-C, Ithaca NY 14850 USA; mjh51@ cornell.edu

\section{Contributors and Supporting Agencies}

Blue Mountain Associates; Feeding Laramie Valley; Whole Community Project; East New Y ork Farms!; Dig D eep Farms; University of Wyoming; Cornell University; and the U.S. D epartment of Agriculture National Institute of Food and Agriculture. minigrants. The evaluation literature on minigrant programs has highlighted their potential for fostering community engagement and supporting ideas brought forward by community members with lived experience of the issue being addressed. In these minigrant programs, the outside funder or distributing agency had largely or entirely determined their structure. In the Food D ignity project, however, the community organizations each designed their own program, led by their community organizers. The diversity of the community organizations and the flexibility and autonomy they exercised in designing their minigrant programs offers an opportunity to explore a novel question:

\section{Author Disclosures}

Hargraves serves on the board of directors and consults for Action Resources International, the sponsoring organization for Feeding Laramie Valley, one of the community organizations that partnered in the Food Dignity project.

\section{Funding D isclosure}

Food Dignity (http:/ / www.fooddignity.org) is supported by Agriculture and Food Research Initiative Competitive G rant no. 2011-68004-30074 from the U.S. D epartment of Agriculture National Institute of Food and Agriculture. 
When community organizers design minigrant programs, what do they choose to build, and why? The analysis in this essay uses an evolutionary evaluation approach to study the Food Dignityfunded minigrant program designs and outcomes, with a view to identifying lessons for future minigrant programs. The paper reports on minigrant program design features, factors shaping program design choices, minigrants awarded by each community organization, and outcomes attributed to the minigrant programs by participants. The principal findings are that program designs differed and that the patterns of difference are consistent with organizational priorities and systemic issues affecting community members. The innovation and variation in minigrant program designs and funded projects are instructive for anyone considering future minigrant programs. An unanticipated finding is that several of the community organizers utilized the design and management of minigrant programs to achieve goals outside of the minigrant funding process. That is, community organizers recognized the program design itself as a way to advance community development goals separately from the support for minigrant projects, and they deliberately selected program features to serve organizational goals. This has implications for community organizers, highlighting internally designed minigrant programs as a promising addition to their strategies. This also has implications for outside funders committed to supporting community-driven change. Given that minigrant programs are often valued as a way to support community-driven solutions to local problems, the results here suggest that minigrant programs can have dual channels of impact, if community organizations design the minigrant programs themselves rather than having features specified externally.

\section{Keywords}

Minigrant; Microgrant; Food Dignity; Community Food Systems; Community-based Participatory Research; Collaborative Pathway Models; Food Justice; Community O rganizer

\section{Introduction}

The Food Dignity project was a five-year, US\$5 million collaborative action research project funded by the U.S. D epartment of Agriculture's Agriculture and Food Research Initiative (USD A-AFRI) beginning in 2011. The goal was to learn from and with five community organizations working to strengthen local food systems and build food justice in their communities. Academic researchers and students came from four universities: University of Wyoming, Cornell University, Ithaca College, and the University of California, D avis. The five organizations that chose to partner in the Food Dignity project came from across the United States: Blue Mountain Associates (BMA) from the Wind River Indian Reservation in Wyoming; Dig D eep Farms (D DF) in the unincorporated areas of Ashland and Cherryland, California; East New York Farms! (ENYF!) in Brooklyn, New York; Feeding Laramie Valley (FLV) in Laramie, Wyoming; and the Whole Community Project (WCP) in Ithaca, New York.

The foundational premise of the Food D ignity project was that community leaders have important and unique understanding and expertise that shape their goals and their approaches to community change (Porter, 2018). The grant included funding for staff, projects, and research in each organization. Another key feature of the sub-award to each community organization was the funding for a minigrant program in each community. Other studies have shown that community minigrants can "stimulate action and expand community control over that action," especially when available to individuals, not just agencies, and when accompanied by catalyzing support (Porter \& Food D ignity Team, 2012). D rawing on this evidence, each community organization in the Food D ignity project was allocated US $\$ 30,000$ to distribute in the form of minigrants. In contrast to other minigrant programs studied in the literature, the minigrant programs were designed by the community organizations, not by the funder or allocating agency (in this case, USD A and the University of Wyoming respectively). This autonomy, combined with the different contexts and priorities of the community organizations in the Food D ignity project, provides a unique opportunity to learn about the potential for minigrants as a mechanism for supporting community change.

This paper uses an evolutionary evaluation 
approach to learn about the design of the minigrant programs and their outcomes (Urban, Hargraves, \& Trochim, 2014). The Food D ignity minigrant initiative was a pilot project at two levels: the community organizations were designing minigrant programs for the first time, and the funded minigrants were pilot efforts for the minigrant recipients. G iven this very early program lifecycle stage at both levels, an evaluation of causality and/ or effectiveness of the minigrant programs or the individual grants would be premature. At this lifecycle stage it is appropriate, instead, to focus on program management and design, with an exploratory examination of reported outcomes (Urban et al., 2014). Accordingly, this paper asks the following: When community organizations design minigrant programs, what do they choose to build, and why? The more specific questions addressed within that are: What were the key features of the community-designed minigrant programs? What considerations influenced those designs? What similarities and differences were there among the minigrant programs, and to what are these differences attributable? What types of community minigrant projects were funded? What outcomes were reported for individual grants and the minigrant programs overall?

We begin below with a review of recent literature on minigrant programs, followed by a description of methods and data sources. Two important aspects of context are summarized next: the expectations and guidelines for minigrant programs that came from the Food D ignity project design, and the situation and characteristics of the community organizations partnering in the Food Dignity project. The results of the minigrant program evaluations are presented and discussed in two parts in order to focus separately on minigrant program design and minigrant project awards. Conclusions and questions for future work are offered in the final section.

\section{Review of Literature on Minigrant Program Design and Goals}

Motivations for Implementing M inigrant Programs In the published literature on minigrant programs, a common motivation cited for minigrants is that they provide a mechanism for increasing community involvement and supporting community ideas. Kegler, Painter, Twiss, Aronson, and Norton (2009) characterize the emphasis on community involvement in many participatory health promotion efforts as reflecting an "implicit... hypothesis that resident involvement in community decision-making leads to better policies and programs, and ultimately to improved community health" (p. 301). Numerous studies of minigrant programs cite their potential for building this kind of community involvement. For example, Bobbitt-Cooke (2005) describes the Healthy Carolinians microgrant project as having "empowered communities and [community-based organizations] to be responsible for community health improvement" (p. 1). Resident mobilization was a primary goal of the $Y$ es we can! community-building initiative in Battle Creek, Michigan, which included a neighborhood minigrant program and aimed to improve outcomes "by mobilizing low-income communities and resident leaders and building their capacity to influence the decisions and policies that impact their lives" (Foster-Fishman et al., 2006, p. 143). The desire to support solutions identified by those with lived experience of the challenges is also a common motivation: "... most mini-grant programs share the goal of promoting bottom-up community building by investing resources in people and neighborhood-based organizations to creatively address the problems that concern them" (Foster-Fishman et al., 2006, p. 146).

Increasing community involvement may involve different objectives, depending on the program's context. Numerous studies cite one or more of these specific minigrant program goals: stimulating community awareness, building community capacity, developing leadership, promoting community engagement or reducing barriers to it, increasing collaborative partnerships with community organizations and groups, and supporting local solutions and diverse grassroots involvement (see for example Bobbitt-Cooke, 2005; Caperchione, Mummery, \& Joyner, 2010; D eacon, Foster-Fishman, Mahaffey, \& Archer, 2009; Foster-Fishman et al., 2006; Foster-Fishman \& Long, 2009; Hartwig, et al., 2006; Monahan, Olson, Berger, \& Sklar, 1993; Smith, 1998). 
In soliciting and supporting certain types of community-based projects, minigrant programs are designed to contribute to the goals of the funding organization, such as improved public health, neighborhood revitalization, increased physical activity, etc. Many examples of minigrant program evaluations come from the arena of public health, such as the 28 reviewed in Porter, McCrackin, and Naschold (2015); however, minigrant strategies have been used in a wide range of fields. The general potential of minigrants, independent of a particular context, is reflected in the case for minigrant programs offered by the Center for Community Health and D evelopment at the University of Kansas, which is included in a chapter on "Establishing Micro-Grant Programs" in its online Community Tool Box. They list potential benefits of minigrant programs, including inspiring creative and innovative thinking; reaching "hard to reach" people; expanding eligibility to grassroots organizations not eligible for traditional grant funding; encouraging smaller, innovative groups who might not respond to larger grant programs; and more (Center for Community Health and D evelopment, 2017).

\section{M inigrant Program D esigns}

Minigrant program designs involve specifying multiple features of the program: the size of potential minigrants, who is eligible to receive one, what types of projects will be considered, how applicants are recruited, what the application process involves, criteria and process for selecting successful applicants, reporting requirements for minigrantees, and so on. The availability of details about minigrant program designs varies among the studies reviewed here. Some studies, such as D eacon et al. (2009), are focused on evaluating outcomes associated with the minigrant program taken as a whole in order to draw conclusions about the potential of minigrant programs in general. This type of study provides fewer details about the design itself. O thers, such as Caperchione et al. (2006), are interested in drawing lessons that would be useful for those designing minigrant programs and so provide much greater detail about program design and management as part of their analysis. With a related goal of presenting ideas and options for future minigrant program designers, this paper shares design features adopted in each of the Food Dignity-supported minigrant programs.

Of particular interest for the current study is strategic decision-making connecting design elements to desired program outcomes. FosterFishman et al.'s (2006) analysis of the neighborhood minigrant component of the $Y$ es we can! project provides an example of deliberate change in program design elements to redirect minigrant program outcomes. The authors describe an evolution in program design from a relatively "non-prescriptive program" that "was initially designed to support almost any resident-initiated effort" (p. 146) to one more strategically designed to align minigrant projects with the goals of the overall initiative and the desire to foster collective action. As the authors recognize, "Because of their connection with larger systems (e.g., the Foundation) and peers, [minigrants] encourage, reinforce, and validate certain community actions and experiences" (p. 148). In this case, the application process was amended to "become more tightly focused on both the process of collective action and the goals of the initiative," including specifying three funding areas into which proposals needed to fit (p. 148). By altering the minigrant program design, the funder was able to direct resources within the arena of community ideas for neighborhood improvement toward projects meeting desired criteria.

My search of the minigrant literature has not succeeded in discovering examples of minigrant programs designed by front-line community organizations, as is the case in the Food Dignity project. Smith and Littlejohn (2007) comment on the potential value of community input in their reflection on community granting by a Regional Health Authority in Alberta, Canada. They come to a strong conclusion, pointing out that community input might have averted a costly design choice:

O ur [Healthy Communities Initiative] emphasized broad participation in visioning, priority setting, program implementation, and evaluation. Yet perhaps the most significant design decision-- the choice of a competitive grant model--was predetermined. In retrospect, it is clear to us that we would have had fewer problems if community 
members had been consulted on this question. They could have shared valued insights about what they saw as the potential benefits and challenges of such an approach, about how well it might fit with local cultures, and about how well it would be received and endorsed. (p. 246)

This acknowledges the value of community input for ensuring that a funder-designed minigrant program will be viable, yet does not go so far as to suggest community-controlled design.

The literature does provide some examples of entities that were close to community-based organizations having control over parts of the minigrant program design. Hartwig et al. (2006) studied the $\mathrm{H}$ ealthy People 2010 initiative in which the Office of Disease Prevention and Health Promotion in the U.S. Department of Health and Human Services selected two different models for awarding minigrants of US $\$ 2010$ to community-based organizations (CBO s). In one model, the O ffice of Healthy Carolinians-- a state agency in North Carolina-- was the issuing agency. The agency decentralized the management and dissemination of the minigrants to a network of 32 community-based partnerships called Healthy Carolinians Partnerships (HCPs). The HCPs developed their own mechanisms for selecting CBO grantees, but all were given the same forms for proposals and the same criteria for awarding grants (Hartwig et al., 2006). The authors provide some description of the variations adopted by the HCPs: "... some partnerships conducted a blinded review process while others targeted agencies new to public health and the HCP to broaden the participation of the partnership and local coalition building for public health" (p. 91). However, the variation or reasons behind it are not the focus of their paper, and no other information is available. Smith (1998) reviews minigrant programs developed independently by four Regional Health Authorities (RHAs) in Alberta, Canada in the mid-1990s. As is reported here with the minigrant programs developed within the Food Dignity project, Smith found considerable variation in the minigrant program designs adopted by the RHAs in the study. He focuses on just two aspects of minigrant program design-- the composition of the decision-making bodies and the nature of support or assistance offered to grantees during the application process and for their projects-- but the reasoning behind the variation does not appear to be available for Smith's analysis, which focuses on perceived outcomes of individual projects rather than the implications of the different design choices.

The above two studies provide examples in which variation in minigrant program design is observed though not explored, and in which the entities designing the minigrant programs are in relationship with community organizations but are not community organizations themselves. This analysis of the Food Dignity minigrant programs, therefore, offers a distinct addition to the understanding of minigrant program potential by presenting cases of community organizations designing minigrant programs themselves, and by providing data on the reasoning behind their design choices.

\section{Methods}

D ata Sources

The principal source of data on minigrant program development and implementation was the set of internal reports submitted annually by each community organization partnering in the Food Dignity project. The report format included a narrative section for their minigrant program, with specific questions about minigrants awarded; the processes for inviting or recruiting applicants, selecting grantees, supporting minigrantees, and tracking minigrant projects; challenges and/ or benefits in "doing" minigrants; and lessons or recommendations on minigrants. The annual reports also requested a list of grants issued during that year, including the dollar amounts awarded and information about the funded projects. (These will be cited below with the format "[Community Organization acronym] Annual Report Y ear X, [calendar year].")

Additional data collected and analyzed for this research included:

- Meeting notes from the second annual Food D ignity project meeting in November 
2011 that included a group discussion of minigrant priorities and concerns.

- Notes and summaries (reviewed by the community partners) from phone interviews conducted in May 2013 with the community organizer in the three most active minigrant programs at that time (ENYF!, BMA, and FLV).

- Transcripts and a summary report from interviews with eight FLV minigrant recipients in late 2013 conducted by two graduate students at the University of Wyoming.

- Notes and a written summary of interviews and meetings with 18 minigrant recipients or steering committee members in June 2014 during site visits to BMA and FLV.

- Participant-observation and associated meeting materials from the minigrant advisory committee for WCP in June 2014.

- Minigrant application forms developed and used by BMA, ENYF!, and WCP.

- Steering committee grant review sheets for WCP and ENYF!

- Nine minigrant reports from individual minigrantees shared directly with Food Dignity by FLV and WCP in various years.

- Videotaped interviews, photo stories, or profiles of 11 minigrantees produced by ENYF! and by FLV.

- Notes from an extended in-person interview in January 2017 with Gayle Woodsum, who served as Community Liaison for the Food Dignity project from O ctober 2013 onwards. In that capacity, she conferred extensively with all the community partner sites, in addition to serving as community organizer and project director for FLV.

D ata A nalysis

In the initial review of the data above I excerpted and logged passages relating to the following aspects of the minigrant programs in each organization: community context factors referenced by program directors, challenges identified by program directors, stated goals of the program, the design of the program (overall structure, application process, selection process, and process for follow-up), overall and individual minigrant program outcomes, and reported lessons or recommendations. I reviewed these items for emergent themes within and across sites and returned to the source materials for confirmation or contradiction.

In addition, a review of the reports of grants awarded in each organization yielded an inventory of all grants including dates awarded, dollar amounts, project names and descriptions, and all information that was provided about project progress, challenges, and outcomes. This inventory was used to generate summary statistics on minigrant grant sizes and, as described more fully later, a categorization of grants according to their purpose (food access, entrepreneurship, and so on) to assess patterns of grant types across the minigrant programs.

In addition to these specific and formal sources, my analysis and approach are informed by having been an active member of the Food Dignity project since the summer of 2011. I was invited to join the project at that time, a few months after the project's launch, to fill the position of evaluator of the minigrant programs. Over time my involvement and responsibilities expanded to include a major initiative to develop collaborative pathway models of each community organization's work. That role gave me greater contact and deeper collaborative relationships with community organizers and staff in each partner organization, and a more nuanced understanding of the vision and strategies connecting the parts of their work (Hargraves \& D enning, 2018). The research conducted for this paper is informed by this experience, integrating the formal analytical components of this research project with the insights and strategic thinking that the community organizations in Food Dignity have shared.

The Food Dignity Collaborative Pathway Models ${ }^{1}$ contributed an additional element to the analysis and interpretation of the project's results. These graphical models were developed from extensive interviews and an iterative revision process with community organizers and key staff

\footnotetext{
1 https:/ / www.fooddignity.org/ collaborative-pathway-models
} 
(Hargraves \& D enning, 2018). The process resulted in detailed representations of the theory of change driving each community organization's work. The models are a graphical form of a program logic model, with arrows linking individual activities to the outcome(s) to which they contribute, and in turn, the outcome(s) to which those contribute, and so on all the way through to the program's desired long-term outcomes. As such, the model of each organization's work presents the community organization's articulated view of the larger body of work within which their minigrant program operates. The particular contribution that minigrants are believed to play is therefore reflected in the way minigrant activities are characterized in these models, and in the causal arrows connecting them to particular short-term outcomes and then on through the subsequent pathways. The models, therefore, provided a mechanism for triangulating results from the other analyses of qualitative data in each program.

\section{Results and D iscussion}

The results are presented in the following four sections: (i) a summary of the guidelines for minigrant programs specified in the Food D ignity grant (to provide context); (ii) a review of the situations, priorities, and readiness of each organization relevant to the development of their minigrant programs; (iii) a summary of the minigrant program designs in each case, with explanations given for features that were adopted; and (iv) a summary of minigrant awards in each case, including the number and size of awards together with information about the types of projects funded, information about individual projects, and reported outcomes. Each of the four sections concludes with a discussion summarizing the results and their significance for the overall study.

$G$ uidelines and Flex ibility in Minigrant

Program D esign

The Food Dignity community support package included US $\$ 30,000$ for each community partner, allocated over the years of the project. There was a

2 In the early Food Dignity project documents the term "microgrants" is prevalent, but usage shifted over time to partial rollout in Year 1 (US\$2,500), the funding peaked in Years 2 and 3 (US\$10,000/ year), and it tapered down in Year 4 (US\$7,500). The community support package also included half-time funding for a community organizer in each organization, whose job would include overseeing and supporting the minigrant program. O rganizations could hold undistributed minigrant funds over from one year to the next. Minigrants could be awarded to individuals, groups, or organizations.

The following points, taken from the Food Dignity grant's Y ear 2 renewal documents and narratives produced by the project's principal investigator, provided some additional clarity and guidance to the community partners ${ }^{2}$ :

- ... steering committees for each community are responsible for dispersing microgrants

- The action goal of these microgrants is to support citizen strategies for building their community's capacity to create sustainable food systems that provide food security.

- Communities will select recipients and the amount for the microgrant or stipend based on local priorities and their assessment of local funding availability.

- [Microgrants] are not loans, 'perks,' or 'gifts.'

(Food D ignity internal memo, "Porter et al. Food Dignity Revisions - Minigrants and Stipends," August 2011)

The original grant proposal and the above clarification both mentioned the use of a steering committee for making decisions about minigrants.

However, there continued to be discussion and uncertainty about the extent to which a steering committee was absolutely required and about expectations or requirements for the composition of a steering committee. Community organizers asked many questions in the early discussions in and after the national team meetings in 2011, such as: What restrictions were there from the Food Dignity project or the funder (USD A) on the types of projects

"minigrants" which is the term used in this paper. 
that could be supported? Were there restrictions on whether people could receive more than one minigrant? Could steering committee members apply for minigrants? Were there restrictions on the size of minigrants, or their timing? Some of these questions had very clear answers (USD A specified for example that minigrants could not be given as loans, perks, or gifts). Beyond that, however, there was flexibility: there was no minimum or maximum grant size stipulated; timing and eligibility were up to the community organization to decide on; the application format was up to the community organization and/ or the steering committees to determine. A full treatment of the internal debates and evolution of thinking on how much flexibility the community organizers had goes beyond the scope of this paper. The salient point that forms the starting point here is that community organizations had control and flexibility in the design of their minigrant programs. This becomes apparent in the diversity of program designs adopted in the various organizations.

O rganizational C ontext, G oals, and M inigrant Program Readiness

A second important starting point for understanding the experience with minigrants in the Food Dignity project is how varied the circumstances of the five partnering community organizations are. Their geography and demographics immediately signal some basic differences in context. D D F operates in a coastal, temperate, and densely populated area in California. FLV and BMA both face high elevation, short growing seasons, and low population density in Wyoming. WCP is based in a small city in an upstate New Y ork agricultural region. ENYF! is in an urban, high-density, culturally diverse neighborhood in Brooklyn, New York. Their initiatives and priorities differed as well. BMA is a small nonprofit organization working to improve food security, health, and sovereignty on the Wind River Indian Reservation in Wyoming through education, research and knowledgesharing; creation of the Wind River Tribal Farmers Market; and support for food production. DDF is a social enterprise urban farm under the umbrella of the Alameda County Sheriff's O ffice's Crime Prevention Unit, working to increase access to fresh, healthy food and create employment opportunities and community vitality in the unincorporated areas of Ashland and Cherryland, California. ENYF! operates as part of the United Community Centers in the East New York neighborhood of Brooklyn, New York and runs and supports youth programs, community gardening, an urban farm, a farmers market, and more to "promote local sustainable agriculture and community-led economic development" (https:/ / ucceny.org/ enyf/). FLV is a communitybased and community-led nonprofit organization in Laramie Wyoming producing food and developing community and backyard gardens, with a focus on health and mentoring, a foundational culture of sharing, and a commitment to cooperative efforts to create sustainable and just food access in Laramie and statewide. WCP was a program within Cornell Cooperative Extension of Tompkins County (CCETC), in Ithaca, New Y ork, focused on community-building, food justice, and increasing the role and voice of marginalized communities in the local food system. WCP ended in 2016, ten years after its inception, with the end of the Food D ignity project funding. The other four organizations continue their work today.

Important differences in their stages of development as organizations also positioned them differently for their minigrant program development. ENYF! was the most established, having already been in existence for thirteen years at the time the Food Dignity project started. Their programming and extensive community connections, and their established focus on and experience with home and community food production gave them a natural starting place for a minigrant program. In addition, ENYF! had prior experience with creating a revolving loan program for gardeners, beginning in 2004, called Backyard Exchange (D aftarySteel \& G ervais, 2015, p. 13). They were interested in extending this program as part of Food Dignity, but since the loan format was prohibited, they transitioned to a minigrant program (D aftary-Steel \& Gervais, 2015, p. 24).

BMA was founded in 2003 and had been operating on the Wind River Indian Reservation since 2008, but began food work only in 2010 just before the Food D ignity project started. The leader of 
BMA had served as a member of a governing tribal council and was well connected to and within the community. The minigrant program opportunity aligned well with BMA's mission of improving health, food production, and food access, and they were well positioned to establish a program.

WCP was founded in 2006 and operated under the organizational auspices of Cornell Cooperative Extension of Tompkins County. CCETC has a long tradition and history of agricultural, horticultural, and food-related programming which gave the larger organization extensive connections in the county's food system networks. However, starting with a change in WCP leadership in 2008, the mission of the project included moving outside those networks to reach and involve those traditionally underrepresented in food system work. In the period between 2008 and 2010, WCP had distributed small amounts of funds to community members in its network and had supported small grant proposals to other agencies that helped launch local food system initiatives. The success of these efforts motivated and formed the basis for the minigrant component of the Food D ignity grant proposal (C. Porter, personal communication, January 22, 2018). The minigrant program was thus well aligned with WCP's goals and vision.

The initiative that became the FLV organization began in 2009, launching its collaborative approach to community change by convening local and regional organizations doing frontline work to strengthen the local food system, and by offering hands-on gardening workshops to the general public. FLV's work took greater hold in 2010 when it helped to install, and subsequently manage, the first community garden to be located in a Laramie city park, as well as a table at the Laramie D owntown Farmers Market to collect food donated by vendors and shoppers for sharing with community members living with food insecurity. The organization quickly expanded, clarifying its mission and driving philosophies and recruiting a team of committed volunteers for program development. It had established a modest yet diverse funding stream for direct service provision at the time the Food Dignity project began. The flexibility of timing, scope, and structure in the Food D ignity project's minigrant opportunity was important to FLV, and
FLV's community organizer "began by researching grant, minigrant, and microgrant history through literature and anecdotal interviews, in an effort to develop a unique, community-driven approach to how grants are offered, who receives them, under what guidelines they are administered, and what they create," (FLV Annual Report Year 2, 2013).

DDF was also committed to increasing food access, health, and opportunity in their community, but was an outlier relative to the other four organizations in several ways. DD F is part of a county government program, operating within the Alameda County Sheriff's O ffice and managed by the Deputy Sheriff's Activity League, an organization that actively engages with numerous community and governmental organizations and funders. It was just a year old at the time the Food Dignity project began, having just been launched as an innovative social enterprise and urban farming venture. Its goals were to increase food access in the larger community, to build the local economy, and to provide workforce opportunities for formerly incarcerated community members.

DDF's early annual reports to Food Dignity described evolving plans for a steering committee and minigrant program in a sometimes turbulent start-up environment. Changing staff and collaborators, emergent funding and partnership possibilities, production challenges from the new farm venture, and the challenge inherent in balancing business and community goals meant that the minigrant program was being explored at the same time that many large and small aspects of the organization were also being adjusted or settled. Against this backdrop, it was difficult for D DF to establish a structure for distributing minigrants even within the flexibility of the Food Dignity parameters. In addition, there was an emerging internal sense that a broad minigrant distribution effort might not be the most effective use of those project funds if the goal was to impact the food system (personal communication, M. Neideffer, February 28, 2018). Minigrant funds were rolled over for the first years of the project and were ultimately distributed through internally-selected community projects relating to the local food system. Because information about their process and minigrants is more limited, and because their experience is 
significantly different from the others, I focus the remainder of this analysis on the minigrant programs of the other four community organizations.

All of the community organizations that partnered in the Food Dignity project are working to strengthen their local food systems. Their approaches to that work are shaped by local priorities, strengths, and constraints in terms of growing seasons, community characteristics, food access, and other factors. Therefore, the community characteristics shared above provide important context for their minigrant program design decisions. Organizational capacity and priorities matter as well, particularly given the administrative and programmatic costs of implementing a minigrant program. Although DDF is set aside for the remainder of the paper, their response to the minigrant opportunity is consistent with the overall observation that the Food D ignity partner organizations designed their minigrant programs in ways that aligned with their priorities and organizational circumstances.

\section{Minigrant Program D esigns: W hat W as}

Chosen, and Why?

Several themes emerged in the group discussion of minigrants at the second national project meeting in November 2011, where community organizers described the thinking behind their minigrant planning. Themes in the group discussion included: how to manage minigrants to ensure successful projects; how to assess feasibility and success; how to avoid issues or perceptions of bias or conflicts of interest; and sensitivity to the risks being taken by minigrant applicants in stepping forward to propose and then lead projects that would be very visible in their communities. In the words of one community organizer, "... the eyes of the community are going to be on the awardee. I don't want to set someone up for failure or use someone for a learning process" (Food D ignity project internal notes, D ecember 2011). These shared concerns together with considerations specific to each community informed their minigrant program designs. Table 1 summarizes answers to the first research question asked in the introduction: What were the key features of the community-designed minigrant programs?

Reading across the rows of Table 1 makes it clear that there are no dimensions of minigrant program design for which all community organizations adopted the same solution. Reading down the columns, on the other hand, speaks to internal consistency within each program. A common thread is that each organization designed their program to fit the community's history, culture, current needs, and community context in ways that reflect their organizational priorities and capacity. All community organizations responded to a common need to overcome the effects of systemic marginalization, which prompted various efforts to build relationships and trust. Beyond that, however, there is no cross-cutting "best practice" design that emerges from these four community organizations. Variety and innovation are the hallmarks of the community-designed minigrant programs funded by the Food D ignity project.

To assess the motivations behind their design choices in more detail, the sections below present additional qualitative data together with analyses of each organization's collaborative pathway model. In all cases, the minigrant programs are aligned with the community organization's larger goals. O ne unanticipated finding is the extent to which community organizations used minigrant design features to serve community objectives directly, rather than through the support for community projects.

\section{Blue M ountain A ssociates}

BMA's focus on health is evident in their minigrant program's emphasis on food production combined with the expectation that grantees participate in the recently-established Wind River Tribal Farmers Market so that other families would also have increased access to fresh, healthy food. As BMA's leaders explained in an early annual report, "The high rate of diabetes and cardiac problems are constantly taking our people out of our lives much too early. We wanted to find a way to help educate and assist members in changing fast food habits and going back to healthy food, home-grown fruit and vegetables" (BMA Annual Report Year 2, 2013). Their commitment to tribal culture and history motivated efforts to restore traditions of food production and healthy dietary patterns and build a sense of possibility and ability. "Elders who know 
Table 1. Minigrant Program Characteristics

The Food Dignity project's fiscal year was April 1-March 31. Abbreviations: SC =Steering Committee; $\mathrm{CO}=$ Community Organizer

\begin{tabular}{|c|c|c|c|c|}
\hline $\begin{array}{l}\text { Program } \\
\text { Component }\end{array}$ & Blue Mountain Associates (BMA) & East New York Farms! (ENYF!) & Feeding Laramie Valley (FLV) & Whole Community Project (WCP) \\
\hline $\begin{array}{l}\text { Launch phases and } \\
\text { timing }\end{array}$ & $\begin{array}{l}\text { Full launch, with first applications } \\
\text { and awards in Year } 1\end{array}$ & $\begin{array}{l}\text { Full launch, with first applications } \\
\text { in Year 1, first awards in April } \\
2012\end{array}$ & $\begin{array}{l}\text { Year } 1 \text { used to research } \\
\text { microfinance systems and } \\
\text { experiences, define options within } \\
\text { FD, and develop program design; } \\
\text { first awards in Year } 2\end{array}$ & $\begin{array}{l}\text { Year } 1-2 \text { grants selected by CO as } \\
\text { SC options and community needs } \\
\text { were explored; SC organized in } \\
\text { Year } 3 \text { for awards early in Year } 4\end{array}$ \\
\hline $\begin{array}{l}\text { Minigrant program } \\
\text { goals }\end{array}$ & $\begin{array}{l}\text { "Increase health and well-being, } \\
\text { through increased } \\
\text { - physical activity from gardening } \\
\text { and home production } \\
\text { - availability of fresh natural } \\
\text { foods to families doing the } \\
\text { gardening } \\
\text { - availability of fresh natural } \\
\text { foods to others through Farmers } \\
\text { Market and other outlets } \\
\text { - local income from sales of } \\
\text { produce" } \\
\text { (Grantees were expected to sell } \\
\text { extra produce at the weekly } \\
\text { seasonal Farmers Market, making } \\
\text { produce more available to } \\
\text { community.) } \\
\text { (Source: BMAAnnual Report Year } \\
\text { 2, 2013, pp. 2-3) }\end{array}$ & $\begin{array}{l}\text { Increase community leadership } \\
\text { and food access through grants } \\
\text { and a supportive application and } \\
\text { review process. } \\
\text { "The goals of the program are to: } \\
\text { - Increase access to food } \\
\text { - Share knowledge about each } \\
\text { project with wider audiences, so } \\
\text { that others can gain from the } \\
\text { project's experience } \\
\text { - Develop sustainable, tangible } \\
\text { projects } \\
\text { - Contribute to applicants' skills } \\
\text { and understanding of financing } \\
\text { mechanisms so that their } \\
\text { funding prospects improve } \\
\text { - Recruit and support the } \\
\text { Steering Committee in ways that } \\
\text { develop and maintain } \\
\text { community connections" } \\
\text { (Source: “ENYF - Potential } \\
\text { Material for Minigrant Report for } \\
\text { Food Dignity } 2012 \text { Annual Report" } \\
\text { based on my interview with CO } \\
\text { Daryl Marshall, April 2013) }\end{array}$ & $\begin{array}{l}\text { Design and manage a grant } \\
\text { program that will } \\
\text { - "identify, acknowledge, mentor } \\
\text { and support individuals, } \\
\text { particularly from marginalized } \\
\text { communities, who are } \\
\text { interested in the idea of } \\
\text { grassroots, community based } \\
\text { and led food system work based } \\
\text { on their interests } \\
\text { - create an environment and } \\
\text { opportunities that increase } \\
\text { potential and possibility for } \\
\text { them to bring their ideas into } \\
\text { existence } \\
\text { - create an environment in which } \\
\text { they develop or strengthen } \\
\text { relationships among themselves } \\
\text { and with the community } \\
\text { - build toward a new, community- } \\
\text { designed and community-based } \\
\text { funding system that does not } \\
\text { replicate the problematic } \\
\text { mechanisms that are the norm } \\
\text { in most places } \\
\text { - support creative, innovative } \\
\text { projects that are food-related } \\
\text { and that benefit the community" } \\
\text { - Source: "FLV - Potential } \\
\text { Material for Minigrant Report for } \\
\text { Food Dignity } 2012 \text { Annual } \\
\text { Report", based on my intenview } \\
\text { with co Gayle Woodsum April }\end{array}$ & $\begin{array}{l}\text { Program goals as stated in } \\
\text { application form in Year 3: } \\
\text { - "Support access to healthy food } \\
\text { to people from low-income } \\
\text { communities; } \\
\text { - Improve the long-term health of } \\
\text { neighborhood/ community } \\
\text { through education and } \\
\text { awareness efforts focused on } \\
\text { nutrition and hunger food } \\
\text { insecurity; } \\
\text { - Create opportunities for } \\
\text { leadership and civic } \\
\text { engagement for individuals who } \\
\text { have not historically been } \\
\text { represented in the food system } \\
\text {..; and } \\
\text { - Generate cooperation and } \\
\text { foster leadership among people } \\
\text { from low-income household in } \\
\text { the community to participate in } \\
\text { the local food system in } \\
\text { Tompkins County" } \\
\text { (Source: Whole Community } \\
\text { Project Food Dignity Minigrant } \\
\text { Application Form, 2014) } \\
\end{array}$ \\
\hline
\end{tabular}


Decision-maker(s) 4-person SC, with exactly equal $\quad$ SC varied somewhat around a representation from the two tribes core of 6; CO actively sought on the Wind River Reservation cultural backgrounds to reflect ENY community. SC met monthly, with activity varying in tune with grant cycle. diversity in ages, languages,

Initial grantees hand-selected by Some grants (initially and

Stipends according to amount of participation in meetings; ongoing person-to-person support

from CO; process streamlined and

ENYF! staff role expanded to reduce time burden on SC members.

\begin{tabular}{ll}
\hline Timing of grant & $\begin{array}{l}\text { Annual, in early spring in time for } \\
\text { growing season }\end{array}$
\end{tabular}

Recruitment or Widespread, through flyers, invitation process newspaper ads, and informal networks

Two cycles per year, awards
usually made in April and November

\section{Widespread, through email and}

mailing lists, community announcements, outreach at events and individually by SC and cO.
Application or award process
SC developed application process, Application with contact info, 9 including written application and interview with SC. Committee wanted to ensure projects were viable and had good potential for success. Applicants submitted a 1-page proposal responding to multiple questions (nature and location of project; expected results and benefits for self, family, and community, timeline; amount of funding required: how funds will be used).
Application with contact info, 9
questions on project (need for it connection to food access, community involvement, timing and steps involved, skills and resources for successful completion, alignment with other activities (if group project)), plus budget and references. $\mathrm{CO}$ worked closely with grantees to support and strengthen proposals. SC also assisted, in
CO mentored or consulted with initial grantees in their roles as grantors. $\mathrm{CO}$, first to include established and then to include emerging leaders from community; subsequent round of grantees identified and supported by first wave of grantees, giving them individual experience in receiving and then giving grants

subsequently) selected by $\mathrm{CO}$

formal Committee established to review applications late in Year 3 , seeking representation from

experienced community business and organizational leaders as well as individuals with experience of food insecurity and/ or those

historically underrepresented in food system decisions

\section{Unspecified}

Annual, on individual schedules Varied

with each grant creating

foundation for a next grant

Person to person, not broadcast publicly

Person to person, and (in Year 3) through announcement on listserves and other outreach

Conversations with $\mathrm{CO}$ (or subsequent grantor), continuing as needed and for as long as needed to ensure a plan that felt right to everyone. The process is motivations, their ideas, and the inherent integrity and value of them as individuals" ("FLV -

Potential Material for Minigrant Report for Food Dignity 2012

Annual Report"'). Proposals could

be written or oral. A project-
Initial and later grants: discussion with/ request to CO; for Year 3 applications with SC: paper or online application form with contact info, 6 questions on project (goals, who served, alignment with Food Dignity goals, projects involved, community support) plus work plan and timeline, budget, and evaluation plan. activities and steps, individuals "guided by their interests and 


\section{Decision-making SC made selections, prioritizing process feasibility, likelihood of success,} and contribution to health and to community.
Process evolved somewhat over time, to reduce time burden on $\mathrm{SC}$ which was considerable. Settled on having SC members each tak on 1-2 proposals to read and present to SC for discussion and to identify additional info needed. Staff follows up and helps finalize decision. Committee seeks projects that are viable, and have community benefit or sharing of knowledge.

\section{$\mathrm{CO}$ and then grantees made}

selections. Process was personcentered rather than project-

centered, and sought established or emerging community leaders leadership potential, with "strong representation from traditionally marginalized community members, .... and a cross section of cultural, racial, financial, gender, generational backgrounds" (FLV Annual Report Year 1, 2012). Also see Goals above. Once grantee was chosen, the project development process cultivated and refined the project ideas into an awarded project plan.

\section{Reporting and On-going support, education, and} follow-up activities senvices for minigrantees to strengthen projects and knowledge-sharing. Monthly follow-up on-site with grantees and SC: "carry-in" or "pot latch" style, so grantees see all projects and can share ideas and support build connections and network. Grantees were given a camera and submitted 3-, 6-, and 12month reports with photos.

Awards and progress of projects were highlighted in social media and through other channels, to promote new proposals and build a sense of possibilities. months to assess and support
SC did a site visit after 3-4 projects, promote success, learm about challenges, take photos, collect receipts. Selected minigrant recipients were highlighted and celebrated, as were other community members with different kinds of involvement with ENYF!, in newsletter profiles

\section{On-going communication and} aried. Year 4 awards requested relationship, grantees expected to a short report after 6 months and stay in touch regarding how project was going, and submit notes and/ or photographs of their work. Two meetings of

minigrantees brought them together to share about their experience among themselves. Two public displays/ receptions with widespread community publicity included photos, videos, and presentations by grantees to share stories and ideas with the community.
Initial and later grants: interna decision by CO; SC convened early in Year 4: Review form for scoring minigrants on 9 criteria (including clarity and quality, viability,

likelihood of success, involvement of under-represented

communities, potential impact re FD goals), then in-person committee meeting to discuss proposals and make decisions. 
how they used to garden at home and families with enough resources have begun to develop gardens. People have memories of their grandmothers or great-grandmothers gardening, so our plans for the Mini Grant gardeners draw on those memories and knowledge" (BMA Annual Report Y ear 2, 2013). The balanced tribal representation on the steering committee was an important part of ensuring that members of both tribes would be treated respectfully and fairly in the minigrant process and that community-driven solutions and ideas would be brought forward. "The purpose of the Blue Mountain Steering Committee was to help us know the needs of the communities and to bring all tribal members together to work on the most critical health issues, seeking solutions and implementing them through programming." (BMA Annual Report Year 3, 2014). BMA's reports recognized the damage done by outsiders and described an acquired caution on the part of community members that they worked hard to overcome: "D ue to the reluctance of tribal members to get involved in new projects, having been disappointed through various government programs over the years, they have learned to be overly cautious. After quietly seeking basic information and hav[ing] been treated with great courtesy and respect, they became enthusiastic and were carefully choosing projects that they felt would benefit both their families and the communities to the greatest extent" (BMA Annual Report Y ear 1, 2012).

The design of BMA's application and steering committee processes, together with features such as the monthly potlatches (social gatherings where each person brings food to share), in which minigrantees and steering committee members visited and spent time with each project, reflected their intentions to promote success, build and share knowledge, and promote positive connections within the community and especially between the two tribes. Expanding and restoring people's sense of what was possible was an important goal. O ne of the themes that emerged in a meeting with steering committee members and grantees, organized by BMA when I visited in June 2014, was reported this way: "O ne speaker remarked that there are so many ventures that fail or simply fade away, that people become discouraged.
There was much emphasis on wanting to show what is possible, and that the aspirations that many community members share can be brought to fruition, with benefits for many" ("Reflections on Food Dignity 'Minigrant Site Visit' to Wind River Reservation and Blue Mountain Associates," Internal Food D ignity report, July 2014).

The collaborative pathway model of BMA's work provides information about how BMA's leadership viewed the contributions of the minigrant programs in the larger context of their organization's overall work. Close examination of their model (see the Appendix for details) shows that funded minigrant projects were seen as contributing to improved access to healthy food for families and community, and to increased capacity for food production--both of which served their larger goals of improving community health. Surrounding support activities that were part of the management of the minigrant program reinforced those goals and worked to increase the success of projects, promote food system entrepreneurship, and expand community aspirations. In addition, the design and management of the minigrant program contribute to a region of the pathway model that is not related to project-generated outcomes of food access, health, or entrepreneurship. Confirming the larger vision and needs seen in the quotes above, the minigrant program was designed specifically to help strengthen relations between the two tribes on the Wind River Reservation, and to expand connections more generally both within and outside the reservation. That is, the opportunity to design the minigrant program in ways that suited their community gave the leaders of BMA opportunities to improve the chances of success for minigrant projects. It also gave them a way to advance important additional goals that extended beyond the food system projects. As such, the minigrant program design operated essentially as a distinct initiative in its own right.

E ast $\mathrm{N}$ ew $\mathrm{Y}$ ork Farms!

ENYF!'s minigrant program also pursued goals beyond the important ones of promoting food production and access. ENYF!'s leadership saw minigrants as an opportunity to strengthen the skills of grantees and steering committee members 
in navigating traditional funding mechanisms, and to expand and share knowledge and promote commitments to community well-being.

The community organizer at ENYF! worked hard to overcome the accumulated effects of historical exclusion and oppression, which made community members skeptical of the opportunity: “... I was proposing such a thing to a historically marginalized community, in which people can sometimes rightfully be suspicious" (ENYF! Annual Report Y ear 1, 2012). ENYF! reported that it was essential to build connections and relationships in the community to engage steering committee members, overcome caution and skepticism, and bring forward community ideas and proposals. Applicants were supported throughout the process:

Right from the beginning, the [steering committee] and [community organizer] work to make the application process very supportive, spending time talking to potential applicants about their projects, and helping them put together an application with enough information and detail.... There is support given not only to grantees, but also to applicants whose projects were not funded. This may include feedback on their writing or project descriptions, connections to other resources or ENYF! community partners who may be more able to assist with the project, and so on. (ENYF! Annual Report Year 2, 2013)

The support provided to applicants whose projects were not funded is an important indication of the larger commitment surrounding the minigrant program. ENYF! recognized explicitly that the impact of the minigrant program was not just coming from the funds provided:

What we have learned throughout this process is that material resources alone are not sufficient. If we just gave out mini-grants or purchased greenhouses or water tanks, we would not see the same impact. It is the relationships that we cultivate and the non-material support that we provide that makes our program effective and ensures that these resources are having broader impacts.

(ENYF! Annual Report Y ear 4, 2015).

The steering committee itself was seen as an important opportunity for building and utilizing expertise, skills, and connections in the community. The committee met monthly, and members received a stipend for their contributions. ENYF! adjusted the application review process after the first round, as it was seen to have placed an excessive burden on steering committee members. The new process incorporated more staff support and adjusted compensation for steering committee members to reduce the burden on them while at the same time creating incentives to participate in meetings and ensuring that each application received a thorough and thoughtful review. The community organizer devoted time and sensitivity to supporting and guiding the steering committee, recognizing their role not only as an important contribution to the community but also as an important opportunity for the members themselves. Commenting on the frustrations steering committee members experienced as part of a "disenfranchised group in a marginalized neighborhood," and their continued dedication over months and years, the writer observed, "O ur meetings were a place of empowerment, where one could have a say in their local food landscape" (ENYF! Food Dignity Final Report, 2016).

This distinct contribution of the minigrant program design is reflected in ENYF!'s collaborative pathway model (see the Appendix). The distribution of minigrant funds contributes to the launching of promising small-scale food-related projects in the community. The steering committee selection efforts together with the design and management of the program help ensure that ideas are brought forward, promising projects are selected that will be useful to the community, and applicants gain skills and expand their capacity for entrepreneurship. These outcomes all contribute to improved access to high-quality fresh food, and to food security. They also contribute to greater entrepreneurship and, ultimately, to community opportunities and community vitality.

One component of the minigrant program contributes to community development in a way 
that does not operate through the funded minigrant projects: the management of the steering committee. This process is presented distinctly in the model as a mechanism for increasing personal growth and leadership for adults in the East New York community. This is consistent with the characterization of the steering committee's work in the quotes above. As was the case in BMA's work, ENYF! utilized the minigrant design freedom to develop a mechanism for serving larger organizational goals separately from the funding opportunity the minigrants provided.

Feeding $L$ aramie $V$ alley

FLV designed the minigrant program to create and test a novel funding mechanism, seeing the minigrant funding as "the first opportunity for FLV to exercise its desire to be a source of nonconventional funding to the community" (FLV Annual Report Year 1, 2012). The hand-selection of grantees and the conversation-based process of arriving at a viable, inspired project scope in the initial round of selection embodied a person-centered rather than project-centered approach. This was used to bring forward a diverse mix of leaders and emerging leaders who might never have trusted or participated in a traditional funding process and to craft projects that were truly aligned with their interests and possibilities. Prospective grantees were invited to propose a project that would be "connected in some way to exploring and/ or supporting the idea of improved food access and equality, and will be of some benefit to the community (you can define the community as long as it's within Albany County)" (from "Minigrant D evelopment for Community Food Projects," the invitation letter to prospective grantees). With this emphasis on their ideas and their sense of community, FLV's minigrant program design was consistent with the overall vision of FLV's work, described as "weaving together individual threads of desire for Albany County to have control over its food system through a unified, community based and led process of power and control equity" (FLV Annual Report Year 2, 2013).

The radical intention of having grantees turn around to become grantors continued the person- centered approach and was intended to ensure that the minigrant process "will be one that evolves through grant giving that simultaneously builds on feedback and guidance from the grant recipients and extends itself into each subsequent granting cycle" (FLV Annual Report Y ear 1, 2012). Several minigrantees reported in follow-up interviews in 2014 that they found the role of grantor to be appealing because it expanded their ability to support other community members and build connections with people. At the same time, they found it to be somewhat challenging. Finding projects and people that are not usually found is, by definition, difficult and took time. Finding a balance between supportive involvement and ceding control to the grantee was not always easy. Moreover, the power of the granting decision could be uncomfortable. In the words of one minigrantee, "Why should I be the one to decide who gets the money?" (personal comment at FLV minigrant recipients meeting, June 30, 2014).

The FLV Collaborative Pathway Model embeds both minigrant design (including the reversal of roles from grantee to grantor) and the distribution of funds for projects in a single activity (see the Appendix). This minigrant element leads to important outcomes, such as increased individual capacity to produce food and increased food production in the community. These outcomes are key contributors to decreased food insecurity in the county and a stronger community-driven food system. It also has effects that arise independent of project funding, effects that arise because the program is designed to ensure that the experience and knowledge of food insecure community members are valued, and that the process will contribute to "Softening lines between giver and receiver." Both of these are strategically critical outcomes in the overall model of FLV's work. As in the other models, the design and management of the minigrant program matter in ways that are distinct from the funds that are distributed in the community. This perspective is explicit in FLV's first annual report, "the [minigrant] program is as committed to structural and process integrity as it is to the actual implementation of any specific project" (FLV Annual Report Year 1, 2012). 
Whole C ommunity Project

WCP operated in a county and region with a large agricultural sector, and many active and well-established food system organizations and groups. Within that context the mission of WCP, as stated in the first annual report, was "to address those issues that perpetuate the burden of chronic health conditions, food insecurity, and low representation of communities of color and people from low-income households in decisions that affect the food system" (WCP Annual Report Year 1, 2012). The initial vision for the steering committee reflected these priorities:

It is the opinion of the project director and the Community O rganizer that a Steering Committee needs to be made up of folks with first-hand experience (or at least very deep understanding) of the challenges experienced by low income folks to meet and sustain basic needs, such as housing, healthy and dependable food access, as well as the impact of racism on food dignity, AND who have a good understanding of food systems and where interventions could significantly enhance a food system and food dignity. (WCP Annual Report Y ear 1, 2012)

As was also reported by ENYF! about the steering committee recruitment effort, WCP's community organizer observed that bringing people who have been excluded from a system into an active role in decision-making within that system raises challenges of unfamiliarity and lack of connection. That, combined with issues of limited time and financial compensation (including how to compensate individuals for their involvement and contributions without violating the terms of any government assistance that they might have been receiving) delayed the formation of a steering committee. In the interim, WCP used discretionary minigrants together with community researcher and animator stipends to support food system projects and begin to build the kind of capacity and availability that they sought for the minigrant steering committee. By the end of Y ear 3 when a minigrant selection committee was formed, it included desired areas of experience and expertise, with representation from current minigrant recipients and community members with experience of living with low income and/ or food insecurity. The minigrant selection committee convened for one round of minigrant awards, which were issued early in Y ear 4. Remaining minigrant funds were distributed through an internal decision process by the community organizer, as they had been prior to the committee's formation (and indeed, though on a smaller scale, prior to the Food Dignity project itself). The Community O rganizer identified potential minigrantees, encouraged and supported their work, and connected them to additional resources and people in the community. This individual support was also provided to minigrantees who received awards through the selection committee process.

In the collaborative pathway model for WCP's work, the minigrant provision of funds and the design of the minigrant program all work toward WCP's long-term goals of increasing the involvement of underrepresented community members in the food system through increased access to resources, entrepreneurship, employment, voice, and power in the food system. O n-going individual, relationship-based support is key to all aspects of WCP's work, including supporting minigrantees by building individual capacity to explore possible food system interests and persist in working toward personal aspirations. In slight contrast to the other community organizations studied here, the use of minigrant program design remains "interior" to the project funding channel, in the sense that there are no design features that are clearly and explicitly presented as operating separately from the minigrant project funding and support for minigrantees. The goals of WCP's minigrant program are no less ambitious and important, but it appears the mechanism for working toward those goals operates through the funding of and support for community projects, and not also through independent channels, such as the the steering committee in ENYF!, the role reversal of grantees and grantors in FLV, or the defined roles for the two tribes in BMA's minigrant program 
design. The difference is subtle in that all four programs clearly designed their minigrant programs for success in supporting community ideas and solutions, and all selected mechanisms and features that were aligned with community needs and organizational capacity.

The design summaries in Table 1 and the additional detail above highlight variation among the organizations' minigrant program designs. The timing of grant cycles and the specific goals of each program differed. The formality and structure of application processes varied (though all were intended to be accessible to community members and all included support for applicants in one form or another). D ecision-making entities ranged from large committees that met once, to on-going working groups, to community organizers and single grantees becoming grantors. Follow-up mechanisms in some programs included group site visits to share information and support, and in other cases relied solely on individual written reports submitted to the community organizer. In each case, the design choices were consistent with organizational goals. BMA was especially interested in increasing food production, and the grant cycle was timed for the growing season. ENYF! used a relatively formal application format, which was intended to build community member's capacity to compete for other sources of local funding. FLV was interested in system change and designed a minigrant program that reversed standard grantmaking practices by focusing on individuals rather than projects and having grantees become grantors in the year following their own project. WCP used a structured application and selection committee process for one major round of grant giving but also relied heavily on one-on-one relationship building and networking to connect with un-

Table 2. Minigrant Counts and Size Ranges

\begin{tabular}{lccc}
\hline Community Organization & Smallest (US\$) & Largest (US\$) & Total \# grants \\
\hline Blue Mountain Associates & $\$ 400$ & $\$ 2000$ & 24 \\
\hline East New York Farms! & $\$ 140$ & $\$ 3,546$ & 36 \\
\hline Feeding Laramie Valley & $\$ 500$ & $\$ 4,299$ & 17 \\
\hline Whole Community Project & $\$ 156$ & $\$ 3,019$ & 15 \\
\hline
\end{tabular}

derrepresented groups in the community in keeping with WCP's overarching mission. In these and other ways detailed above, the similarities and differences across programs can be seen to reflect organization-specific priorities and circumstances. Moreover, the internal coherence in all these programs and their individuality suggest that control over minigrant design was important in allowing the organizations to integrate their minigrant programs into their organization's work and contribute to fulfilling organizational goals. For at least three of the organizations, that design control also facilitated an innovative strategy in which design features in their own right served as valued mechanisms for advancing organizational goals through a channel that was separate from the minigrant project channel.

Minigrant A wards

Minigrant program results in terms of funded minigrant projects reflect a combination of the kinds of projects that were brought forward for consideration, the priorities of the community organizations and their minigrant programs, as well as the strength of the individual proposals and the perceived viability of the projects. Each of the four minigrant programs supported a diverse set of projects as described below.

Minigrant sizes and numbers

Collectively, these four community organizations distributed 92 minigrants over the course of the Food Dignity project. A snapshot of minigrant numbers and size ranges in each program is provided in Table 2 . Chart 1 shows the pattern that emerged in each organization in terms of the range of sizes of individual minigrants they awarded.

None of the community organizations specified a minimum or maximum size for individual minigrant awards. FLV did set a fixed grant amount in its first round (US\$1500), but the amounts in subsequent awards varied. Inevitably, minigrant award sizes reflect the combination of the nature and scope of projects proposed by 
Journal of Agriculture, Food Systems, and Community D evelopment ISSN: 2152-0801 online

Chart 1. Percentage of Minigrants Issued in Each Size Range

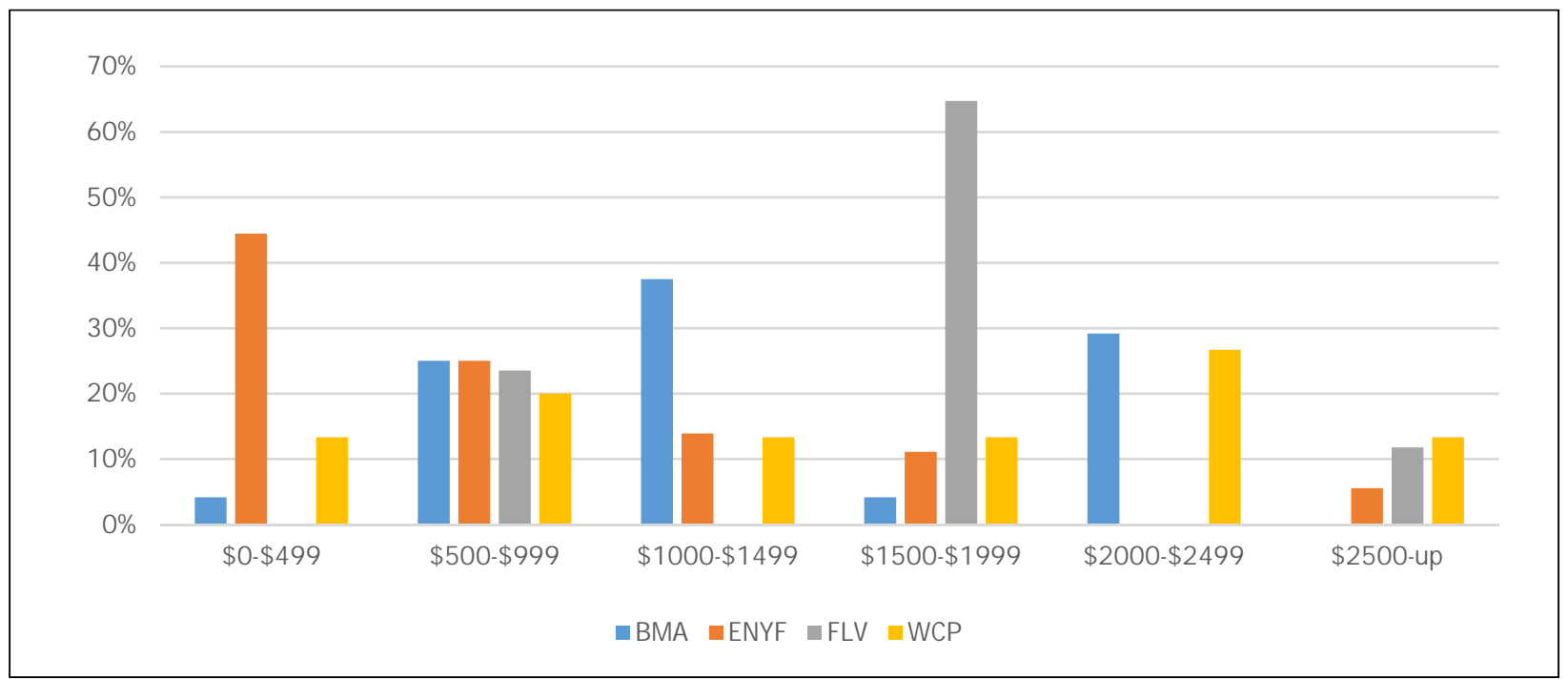

community members and the community and organizational priorities in the selection process. In discussions at an early Food D ignity meeting, some community organizers questioned the potential impact of small grants, making the point that larger grants that would support more substantial projects, though there was also sentiment in favor of supporting more people and ideas by giving a greater number of smaller grants (Food D ignity project internal notes, D ecember 2011). Table 2 and Chart 1 indicate that ENY F! gave out larger numbers of smaller grants, while FLV gave out fewer, generally larger grants. BMA and WCP tended to cover all size ranges somewhat more evenly. However, there is not enough information to draw conclusions about this as a strategic choice on the part of the community organizers.

\section{Minigrant Project Types}

Minigrant recipients proposed a wide variety of projects and desired outcomes. To explore potential patterns in the types of projects that were proposed, I categorized the 92 minigrants issued by these four community organizations according to project type. The level of detail available on projects varied. In some cases, only the project title and a brief description were available; in others, there were more detailed references to a project in multiple annual reports and minigrant summaries. Because it was difficult to distinguish consistently between, for example, a project that was solely for home food production, solely for community-destined food production, or involved both, some potentially interesting distinctions were necessarily subsumed into the broader categories presented in Table 3.

Projects were categorized in terms of the changes they were working to bring about, rather than the activities they were proposing to do to achieve those changes. This meant that, for example, season extension projects (greenhouses) were grouped with food production projects because all of them served to improve the availability of fresh produce. An alternative characterization scheme, one that focuses on the activity rather than the intended purpose(s), would also be a valid and useful approach. However given the diversity of contexts in which these four minigrant programs operated, it seemed more fruitful to look for commonalities and uniqueness in intended ends, rather than in the means to those ends.

The counts in Table 3 are conservative, as I erred on the side of not attributing a category unless it was explicit in the project information (for example, there were likely many more BMAsupported projects on the Wind River Reservation that resulted in increased community access to fresh food through sales of extra garden produce at the Wind River Tribal Farmers Market, since this was a general expectation of all minigrant 
Table 3. Diverse and Multiple Purposes of Minigrant Projects

The column totals exceed the number of grants awarded by those organizations because grant projects often served multiple purposes.

\begin{tabular}{lcccc}
\hline Minigrant Project Purpose & BMA & ENYF! & FLV & WCP \\
\hline Increase availability of fresh locally produced food (home \& community) & 22 & 8 & 12 & 1 \\
\hline Increase shared community capacity for food production and preparation & 1 & 13 & 5 & 4 \\
\hline Increase interest in and access to fresh, healthy food (transportation, markets) & 8 & 9 & & 3 \\
\hline Increase availability of and capacity for disability-inclusive gardening & & & 3 & \\
\hline Expand or strengthen local entrepreneurship in the food system & 8 & 2 & 5 & 2 \\
\hline Increase the availability of culturally important crops & 3 & 1 & & \\
\hline Increase knowledge sharing resources (demonstration projects, materials) & 4 & 4 & 6 & 1 \\
\hline Increase knowledge of gardening, food prep, nutrition, through workshops & 19 & & 4 \\
\hline Increase community networks and connections around health and/or well-being & & & 6 \\
\hline Increase youth interest, knowledge, and/ or opportunities in food and food systems & 6 & 4 \\
\hline
\end{tabular}

recipients, but the extent to which this was done was not always explicit in the annual report descriptions of individual projects.)

Not surprisingly, given the context of the Food Dignity grant and the missions of the community organizations, all the minigrant programs funded projects involving food production, expanding community capacity for food production, and increasing knowledge about food production, food preparation, and nutrition. All minigrant programs also funded projects specifically related to supporting entrepreneurship in the food system. Both ENYF! and WCP funded projects that specifically involved youth or families with children. FLV had several projects that specifically related to creating more ability-inclusive gardening opportunities. WCP was distinct in funding multiple projects that related to creating connections among community members and networks, organized around issues relating to health and nutrition. BMA and ENYF! were distinct in having projects that specifically focused on cultural foods and restoring cultural practices around food. This is consistent with their particular cultural and historical contexts.

To bring life to the broad categories in Table 3, Table 4 lists specific projects underlying those categories.

O utcomes A ttributed to M inigrant Projects and Programs

As mentioned earlier, these minigrant projects were pilot projects for each of the minigrant recipients, and evolutionary evaluation principles indicate that it is not appropriate at such an early program lifecycle stage to try to assess causality or draw definitive conclusions about project impacts (Urban et al., 2014). However, we do have reports of outcomes and feedback on the minigrants provided by grantees and the community organizers in individual minigrant reports, organizational annual reports, and in-person interviews which give important insights into how these projects were perceived and valued internally. These are summarized below.

Blue M ountain A ssociates

The impacts attributed to the minigrant program by BMA leadership and steering committee members were wide-ranging, beginning with food produced but extending into community health, community relationships, and learning. Minigrantees "became steady vendors at the Tribal Farmers Market, as their crops produced more than their families, relatives, and friends could use" (BMA Annual Report Year 2, 2013). The increased availability of fresh food at the Farmers Market mattered to community members, "The community members who shopped at the Markets were so pleased to find all the fresh produce right at hand, and they took a lot of pride in the fact that it was their people who had accomplished this" (BMA Annual Report Y ear 3, 2014). Steering committee 
Journal of Agriculture, Food Systems, and Community Development

ISSN: 2152-0801 online

https:/ / www.foodsystemsjournal.org

Table 4. Funded Minigrant Projects for Each Organization

New or enlarged gardens, root cellars, and greenhouses; a free-range organic chicken farm for home and
community food consumption; research on restoring the production of ceremonial tobacco; production of
traditional varieties of Indian corn and traditional medicinal herbs; research on seed varieties; value-added salsa
and other products; and diverse additions to the types of vendors and availability of fresh healthy food at the
weekly seasonal farmers market.

Multiple garden projects and community gardening capacity in the form of tools, greenhouses, and climate-control equipment for greenhouses; a seed saving and sharing project to support culturally favored foods from the

ENYF! diverse communities in East New York and to promote cross-cultural connections; a van shuttle for seniors to provide access to the Farmers Market; a soup kitchen's purchases of fresh produce so that it could help increase healthy food consumption in the neighborhood; projects in after-school programs to increase youth interest in fresh foods by using a juicer or creating fresh healthy snacks; and a wide variety of cooking classes.

Educational signage and food information at a community garden; disability-accessible garden development; a submersible pump to improve the water supply for a food gardening and production project in a rural area constrained by severe water challenges; development of garden sharing projects creating new types of community

FLV gardens; development of two Community Yard Share gardens; miniature greenhouse demonstration projects; helping to establish a community garden in a part of Laramie with particularly high food insecurity; a special needs individual garden and community service project; infrastructure and equipment for an entrepreneurial turkey business; a poultry barn and several backyard chicken projects; first-person research on and sharing of information on how to improve accessibility and inclusion in food system programs and projects; and knowledge building and sharing through sustainable foods and leadership conferences.

Infrastructure and equipment for educational farming demonstration projects; community gardens; food distribution through a community-integrated organization in a rural area with high food insecurity; general and

WCP volunteer-focused support for a community market in a low-income part of town; an intergenerational gardening project; events and gatherings to build connections among people interested in health and well-being; family wellness programs including healthy eating and activity; food system entrepreneurship; knowledge-building around food-based natural health; and youth internships and apprenticeships to build skills for entrepreneurship, community engagement, and management.

members, BMA leadership, and minigrant recipients at a June 2014 site visit emphasized important spillover effects:

Several people commented on how important the Farmers Market has become within the community in terms of food availability, healthier eating, strengthening connections in the community, and sharing knowledge. They also commented on benefits in terms of relations with those outside the Reservation who now come to the market and as a result get to know a bit more about the Reservation and how to get around, overcome stereotypes, and reduce barriers to interactions. ("Reflections on Food Dignity 'Minigrant Site Visit' to Wind River Reservation and Blue Mountain Associates," Internal Food Dignity report, July 2014).

The benefits attributed to the minigrant program are related to the program overall and the way it was designed and managed, rather than simply to the infusion of project funds. As noted earlier, the system of monthly potlatches at minigrant project site visits contributed to communitybuilding and a sharing of ideas and knowledge. O ther program features had impacts as well. As reported by BMA,

The exciting thing about the Mini Grant projects was the learning process. So many people came in on their 3-month evaluations, handed in their proper paper work regarding accounting process and pictures of progress, and asked all kinds of questions - the simple process of putting in a garden, which looked so easy when parents and grandmothers had done it, they were surprised to find the amount of work and dedication it took to get the job done. (BMA Annual Report Y ear 2, 2013).

The minigrant discussion in the June 2014 
meeting of the steering committee and minigrantees emphasized the larger impacts:

This is how one member of the group summarized the overall effort of the minigrant program. She commented, and others concurred, that what is powerful here is that everyone in the group has strengths and shares their particular talents and abilities so that the whole group is strengthened. Individuals have diverse strengths in gardening and horticulture, as a Master Electrician, as Master G ardeners, in construction, in food preparation, in nutrition, and many other areas that benefit everyone in the group. The connections among them are a vital and powerful component of what is being "built" here, going well beyond the immediate food production projects. This ever-strengthening fabric within the group conveys a moving sense of sustainability and strength. As one member of the group commented, 'This isn't just building community, it's family.' ("Reflections on Food Dignity 'Minigrant Site Visit' to Wind River Reservation and Blue Mountain Associates", Internal Food D ignity report, July 2014)

\section{E ast $\mathrm{N}$ ew $\mathrm{Y}$ ork Farms!}

The annual reports from ENYF! report numerous positive outcomes relating to food production, increased production capacity, increased awareness of food production and food system issues, new interest in healthier eating, and sharing of knowledge. There is also a striking focus on individual growth and transformation, with references to grantees who have gone on to receive funding from other sources, who have gone on to new roles as community educators, who have developed ongoing collaborations, or who have expanded their role in the community.

I think an overall impact from this program is seeing more confident repeat grant applicants. More people have become independent and have searched out other grant sources in addition to ours. Many have shared that they have gotten the confidence to do so through our grant process. This has led to more gardeners, individuals, and schools being more resourceful. (ENYF! Food D ignity Final Report, 2016)

The reports also cite valued outcomes relating to the minigrant program overall, "... people feel comfortable sharing ideas with us. They know they can dream, and know that we will encourage them to be realistic about timeline and budget. This trust is not tangible, but is very important when doing community work" (ENYF! Annual Report Y ear 3, 2014). In the year following the end of the Food Dignity project funding, ENY F! received US\$10,000 from another local funder to continue their minigrant program, which points to a positive valuation of this program in the community.

F eeding L aramie $\mathrm{V}$ alley In follow-up interviews in late 2013 with FLV's first seven minigrant recipients, grantees cited numerous positive outcomes which were summarized by the interviewers as follows:

Participants listed a number of positive effects on themselves, their family, and their community including: increased ability to share with others, more time for volunteering, pride, community education, enabling people to grow, enabling people to increase financial security, increased community interest, and increased communication and social network.... O ther successes included increased free time, increased food production, providing lasting infrastructure, peace of mind, enabling people to help others, overcoming a lack of resources, increased knowledge, reduction of food production costs, and increased communication. (FLV Minigrant Themes, Food Dignity internal report, March 2014)

In the 2013 interviews, grantees particularly cited the benefits of having a process without a lot of stipulations, restrictions, or formal requirements because it freed them up to design and adjust as needed and focus on the project rather than the paperwork. Moreover, as one minigrant recipient put it simply, "It was nice to have my ideas valued."

In the words of the community organizer, 
"... it has become very clear that a real investment in patience, time and personal relationship building with individual community members is key to successful outreach, access, and ultimately implementation of a minigrant for... community based people... who are not accustomed to being supported in making their community food project dreams come true" (FLV Annual Report Y ear 2, 2013). FLV's commitment to the minigrant program has continued beyond the Food Dignity project, as they are building the potential for a continuing minigrant program into all community food-related grants they write, including their recent successful USD A Community Food Project grant (G. Woodsum, personal communication, February 22, 2018).

Whole Community Project

Minigrant Final Reports and summaries of outcomes from WCP indicate diverse positive outcomes relating to increased community connections, friendships, and networks, access to new garden-related resources and knowledge, growing personal voice relating to health and community well-being, increased food access and affordability (in the words of one participant, "If it weren't for Healthy Tuesdays I wouldn't be able to afford my medicine"), increased volunteerism within a community where low income usually prevents participation, expanded and more successful community gardening, and more. In a commentary on the minigrant program overall, one grantee thanked the community organizer for "helping our communities understand the importance of being a part of the solution."

\section{Conclusions and Further $Q$ uestions}

Given the diversity among the community organizations and the flexibility and autonomy they exercised in designing their minigrant programs (in contrast to other minigrant studies), the Food Dignity project offers an opportunity to explore a novel question: When community organizers design minigrant programs, what do they choose to build, and why? The more specific questions addressed within that are: What were the key features of the community-designed minigrant programs? What considerations influenced those designs? What similarities and differences were there among the minigrant programs, and to what are these differences attributable? What types of community minigrant projects were funded? What outcomes were reported for individual grants and for the minigrant programs overall? In answering these questions, this paper moves beyond the boundaries of a program-focused evaluation study and into the realm of exploratory applied research in seeking lessons for use in future minigrant programs.

The numerous benefits attributed to the projects funded by these community-designed minigrant programs support the kinds of observations that have prompted the adoption of minigrant programs in many settings described in the literature on minigrants. Community members have ideas about how to address community needs, and important benefits can follow from supporting and funding those ideas. All four of the communitydesigned programs discussed here paid particular attention to ensuring that minigrants would not just be "available" to community members without experience or expectations of getting funding for their ideas, but that the minigrant program would be inviting, supportive, and sensitive to historically excluded community members and that the invitation, selection, and follow-up processes would be attuned to the realities of life and challenges in the communities.

The principal findings here are that minigrant program designs differed across these four community organizations, and the patterns of difference are consistent with their organizational priorities in term of goals for community change and the situations and systemic issues affecting their communities. There are no singular "best practices" highlighted here; rather, there are principles of internal and community alignment that underscore the importance of having flexibility in design. The minigrants were valued both by the community organizers managing them and by minigrant recipients.

What particularly stands out about these minigrant programs is that the community organizers approached the design of their minigrant programs from a larger view of their potential contribution. Important as it is to fund and support ideas and solutions developed by those who are living with the challenges these organizations are working to 
overcome, their strategic design decisions turned the minigrant program processes themselves into initiatives with outcomes. It's not that the idea that "design matters" is completely new; indeed, examples given in the literature review illustrate just this kind of awareness. What's innovative about the community-designed minigrant programs here is the way that community organizers used the design and management of their minigrant programs - not just the provision of minigrant funds- to further specific organizational goals. BMA designed their program not just to find and support good community food projects, but to build and repair long-strained relationships between the two tribes on the Wind River Indian Reservation and to strengthen community networks and mutual reliance. ENYF! recruited and supported steering committee members not just to ensure good minigrant selections, but as a leadership development opportunity for the individuals themselves. FLV's unusual design of having grantees become grantors deliberately shifted the familiar patterns of decision-making authority so that it was not just that community members' project ideas were valued but that they would gain experience and skills in decision-making roles.

A standard process and early outcome evaluation, such as initially envisioned for Food Dignity, treats minigrant programs as mechanisms for getting funds out to the community. That is certainly an important function. However, it overlooks the innovative and specific potential of the minigrant programs, by deliberately strategic, communitycontrolled design, to be instruments of change in and of themselves. The community organizers in Food Dignity saw the potential benefits of this approach and implemented it in their minigrant programs. This adds an entirely new basis for assessing minigrant programs.

Creating, administering, and managing a minigrant program was a time-intensive effort for the community organizers, other staff, and any steering committee members involved. Future minigrant programs should not underestimate what it takes to manage for success, particularly given the personto-person approach that was characteristic of all the programs here. Beyond these costs, however, there are other questions to ask about how well a minigrant program fits a particular organization. DD F's competing demands as a brand new organization at the time Food Dignity started suggests that timing matters. O rganizational readiness and the potential usefulness relative to larger goals of the organization also affect how feasible or appropriate a minigrant mechanism might be. The nature of the costs, tradeoffs, and potential value for organizations should be explored more thoroughly in future work.

Interesting and important tasks for future work would be to explore more deeply the design choices community minigrant program developers make, the alternatives they consider when contemplating a minigrant program, and why they choose the particular features they do. The analysis here has identified many strategic connections, but these could be explored more fully. It would also be interesting to learn how effective a change mechanism they consider minigrant programs to be, compared to the other strategies they are already using or want to use.

The innovative approaches to minigrant design and management adopted by these community organizations and the positive outcomes attributed to them within the communities suggest that we can think about minigrant programs in a larger way. The value cited for minigrant programs in the literature is typically stated in terms of the importance of supporting community members' solutions to community needs and problems. The work of the community organizations in the Food Dignity project enlarges that idea by showing that community design of minigrant programs may expand their value even further, providing a distinct addition to the tools available to community organizations for supporting desired change in their communities.

\section{Acknowledgments}

The author is grateful to the action research team of Food D ignity and especially to the staff and leadership of the community organizations who designed, managed, and shared their insights about their minigrant programs in their communities. 
Journal of Agriculture, Food Systems, and Community Development

ISSN: 2152-0801 online

https:/ / www.foodsystemsjournal.org

\section{References}

Bobbitt-Cooke, M. (2005). Energizing community health improvement: The promise of microgrants. Preventing C hronic D isease, 2(Special Issue), A16. Retrieved from https:// www.ncbi.nlm.nih.gov/ pmc/ articles/ PMC1459464/pdf/ PCD 2SIA16.pdf

Caperchione, C., Mummery, W. K., \& Joyner, K. (2010). WALK Community G rants Scheme: Lessons learned in developing and administering a health promotion microgrants program. H ealth Promotion Pradiœ, 11(5), 637-644. https:/ / doi.org/ 10.1177/ 1524839908328996

Center for Community Health and D evelopment, University of Kansas. (2017). Establishing micro-grant programs. In C ommunity Tool Box (Chapter 44, Section 2). Retrieved from http:// ctb.ku.edu/ en/ table-ofcontents/ finances/ invest-in-community-resources/ microgrant/ main

D aftary-Steel, S. \& G ervais, S. (2015). East New Y ork Farms! Retrospective case study. Retrieved from http:/ / goo.gl/ fD tqmr

Deacon, Z., Foster-Fishman, P., Mahaffey, M., \& Archer, G. (2009). Moving from preconditions for action to developing a cycle of continued social change: Tapping the potential of mini-grant programs. Journal of $\mathrm{C}$ ommunity Psychology, 37(2), 148-155. https:/ / doi.org/ 10.1002/ jcop.20285

Foster-Fishman, P. G., Fitzgerald, K., Brandell, C., Nowell, B., Chavis, D ., \& Van Egeren, L. A. (2006). Mobilizing residents for action: The role of small wins and strategic supports. A merican Journal of C ommunity Psychology, 38(3-4), 213-220. https:/ / doi.org/ 10.1007/ s10464-006-9081-0

Foster-Fishman, P., \& Long, R. (2009). The challenges of place, capacity, and systems change: The story of Y es we can! The F oundation R eview, 1(1), Article 6. https:/ / doi.org/ 10.4087/ FOUND ATIO NREVIEW-D-09-00005

Hargraves, M., \& D enning, C. (2018). Visualizing expertise: Collaborative pathway modeling as a methodology for conveying community-driven strategies for change. Journal of A griculture, F ood Systems, and Community D evelopment 8(Suppl. 1), 101-115. https:// doi.org/ 10.5304/ jafscd.2018.08A.005

Hartwig, K. A., Bobbitt-Cooke, M., Zaharek, M. M., Nappi, S., Wykoff, R. F., \& Katz, D . L. (2006). The value of microgrants for community-based health promotion: Two models for practice and policy. Journal of $\mathrm{Public} \mathrm{H}$ ealth M anagement Practice, 12 (1), 90-96. https:/ / doi.org/ 10.1097/ 00124784-200601000-00015

Kegler, M. C., Painter, J. E., Twiss, J. M., Aronson, R., \& Norton, B. L. (2009). Evaluation findings on community participation in the California Healthy Cities and Communities program. H ealth Promotion International, 24(4), 300310. https:/ / doi.org/ 10.1093/ heapro/ dap036

Monahan C., Olson L., Berger L., \& Sklar D . (1993). Mini funds, maxi impact: subcontracting injury prevention projects [Notes from the Field]. A merican Journal of Public H ealth, 83(10), 1487-1489.

https:// doi.org/ 10.2105/AJPH.83.10.1487

Porter, C. M. (2018). Triple-rigorous storytelling: A PI's reflections on devising case study methods with five community-based food justice organizations. Journal of A griculture, F ood Systems, and C ommunity D evelopment, 8(Suppl. 1), 37-61. https:/ / doi.org/ 10.5304/ jafscd.2018.08A.008

Porter, C. M., \& Food Dignity Team. (2012). Minigrants: L essons from the literature (Food Dignity Practice Brief 1). Retrieved from https:/ / docs.wixstatic.com/ ugd/ c0c10a 7dac5c0d83e84f9087457db3396d00f6.pdf

Porter, C. M., McCrackin, P. G., \& Naschold, F. (2015). Minigrants for community health: A randomized controlled trial of their impact on family food gardening. Journal of Public $\mathrm{H}$ ealth $\mathrm{M}$ anagement Practice, 22(4), 379-386. https:// doi.org/ 10.1097/ PHH.0000000000000359

Smith, N. (1998, June). L essons from a comparative study of community grant programs in A lberta $\mathrm{H}$ ealth A uthorities. Paper presented at the annual meeting of the Canadian Evaluation Society, St. John's, Newfoundland, Canada. Retrieved from https:// eric.ed.gov/ ?id=ED 427024

Smith, N., \& Littlejohns, L. B. (2007). A case study of community grant funding: Lessons learned. A merican Journal of $\mathrm{H}$ ealth E ducation, 38(4), 242-248. http:// dx.doi.org/ 10.1080/ 19325037.2007.10598978

Urban, J. B., Hargraves, M., \& Trochim, W. M. (2014). Evolutionary evaluation: Implications for evaluators, researchers, practitioners, funders and the evidence-based program mandate. E valuation and Program Planning, 45, 127-139. https:/ / doi.org/ 10.1016/ j.evalprogplan.2014.03.011 


\section{Appendix: Supplementary Evidence on Minigrant Program Strategies from the Community Organizations' Collaborative Pathway Models}

The full collaborative pathway models for BMA, ENYF!, FLV, and WCP are available at https:/ / www.fooddignity.org/ collaborative-pathway-models. Each collaborative pathway model was developed in close collaboration and through an iterative process with the leaders of the community organizations, resulting in a graphical representation of the strategies and theories of change underlying their work (Hargraves \& Denning, 2018, in this issue). As such, the minigrant-related parts of these models provide information about how the community organizers viewed the contributions of the minigrant programs in the larger context of their organization's overall work. This Appendix presents the subsection of each organization's model that covers their minigrant program. It also describes the contributions that each organization attributed to minigrant project funding and, separately, to overall minigrant program design and management.

\section{Blue Mountain Associates}

Figure A1. Subsection of Blue Mountain Associates (BMA)'s Collaborative Pathway Model Relating to Minigrants

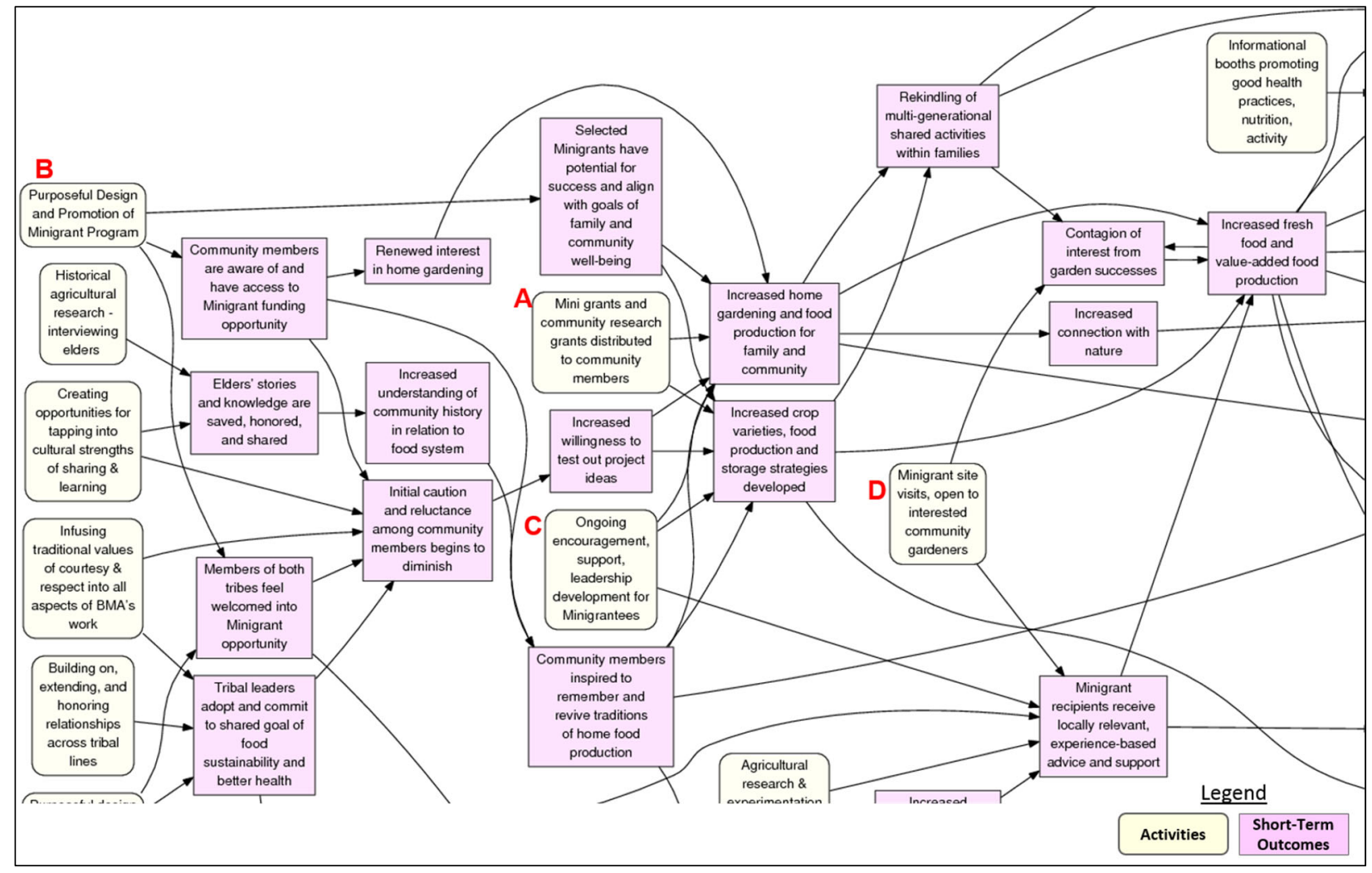

There are four distinct activities related to minigrants in BMA's model. O ne is about the funding provided by minigrants ("Mini grants and community research grants distributed to community members" [marked "A" in Figure A1]). The other three single out features of the minigrant program design and management. An activity titled "Purposeful design and promotion of minigrant program" (B) contributes to three short-term outcomes having to do with the potential for success and the alignment with goals relating to family and community well-being; community members being aware of and having access to minigrant funding; and members of 
both tribes feeling "welcomed into minigrant opportunity." That last short-term outcome about the two tribes feeds into a midterm outcome about increased collaboration between the tribes, which in turn contributes to relationships within and beyond the reservation. The other two minigrant process-related activities are "Ongoing encouragement, support, leadership development for Minigrantees" (C), and "Minigrant site visits, open to interested community gardeners" (D). These two activities are seen as contributing to food production outcomes, increase in access to locally relevant knowledge, and contagion of interest.

\section{East N ew York Farms!}

Figure A2. Subsection of East New York Farms! (ENYF!)'s Collaborative Pathway Model Relating to Minigrants

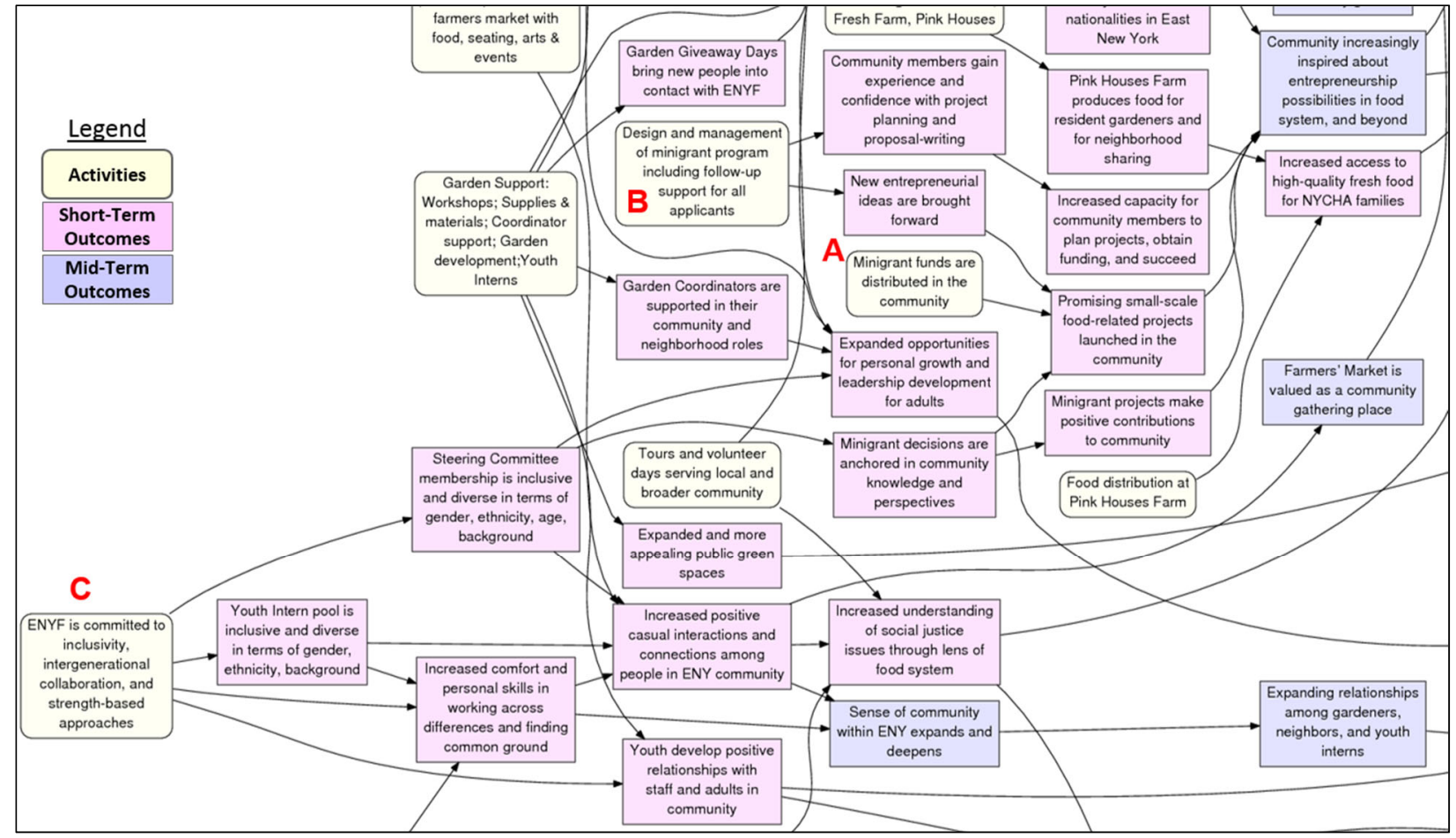

There are three elements relating to minigrants: $O$ ne is an activity specifically about the funding, "Minigrant funds are distributed in the community" (marked "A" in Figure A2), which contributes to a short-term outcome of "Promising small-scale food-related projects launched in the community." This feeds, in turn, into a pathway about entrepreneurship and economic vitality. A second minigrant activity is about the minigrant process, "D esign and management of minigrant program including follow-up support for all applicants" (B), which contributes to community members gaining "experience and confidence with project planning and proposal-writing." This feeds into building project management and funding skills, and on into the entrepreneurship and economic vitality outcomes. The third element related to the minigrant program has outcomes that operate, at least in part, separately from the effects associated with the funding of community minigrant projects. This separate effect is visible in a causal pathway that links ENYF!'s foundational philosophies about how they work with community members to outcomes about community leadership and interconnectedness. This thread can be seen originating at point $C$ in Figure 2, with the activity "ENYF is committed to inclusivity, intergenerational collaboration, and strength-based approaches." This contributes to community 
outcomes in several ways, one of which is to the short-term outcome about the steering committee composition. The steering committee helps by ensuring that "Minigrant decisions are anchored in community knowledge and perspectives," but is also seen as leading to the outcome of "Expanded opportunities for personal growth and leadership development for adults." This reflects the way that the supported steering committee work served an important organizational goal for ENYF!, separately from the funding of community food system projects.

\section{Feeding Laramie Valley}

Figure A3. Subsection of Feeding Laramie Valley (FLV)'s Collaborative Pathway Model Relating to Minigrants

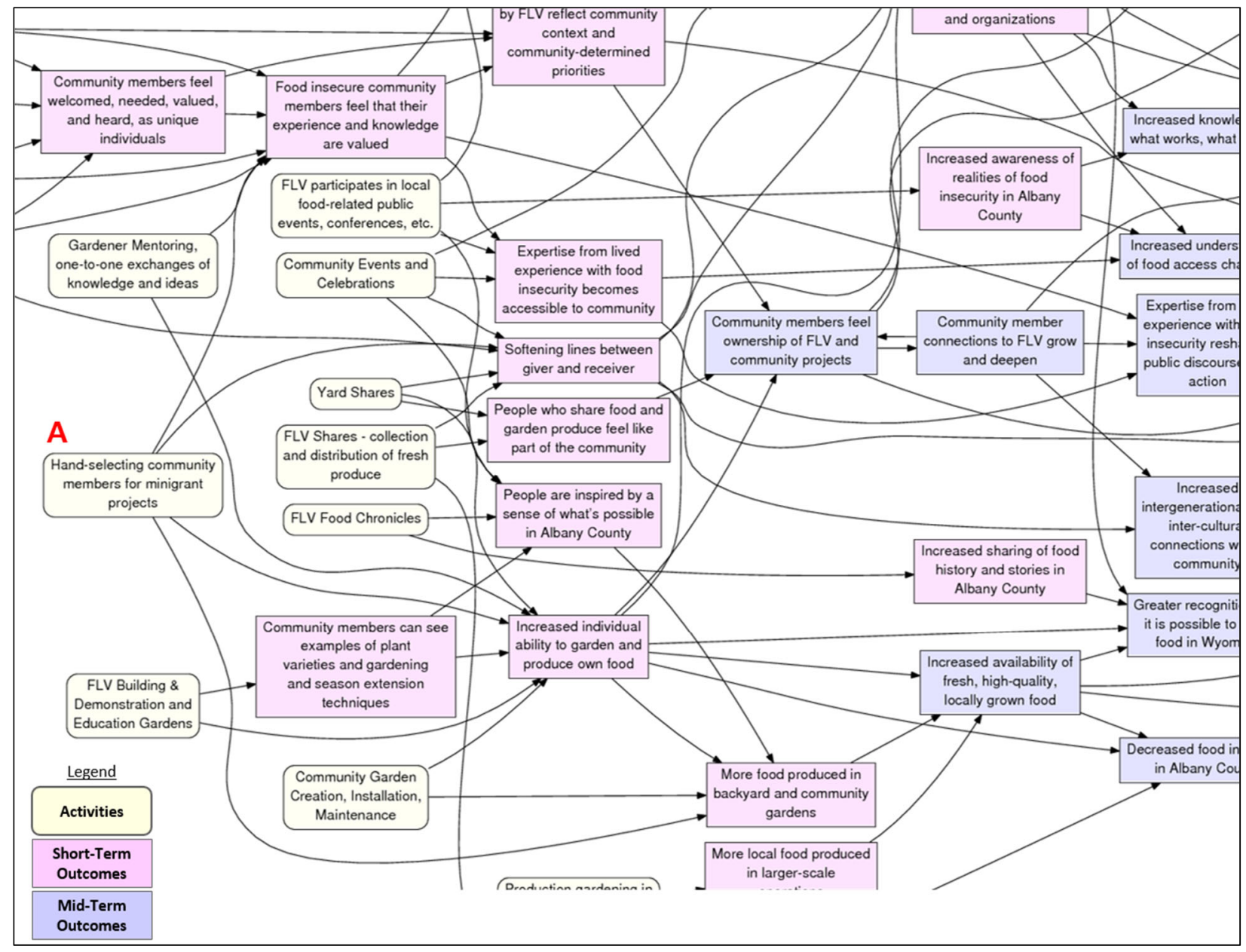

The FLV Collaborative Pathway Model has only one activity that specifically refers to the minigrant program, "Hand-selecting community members for minigrant projects" (marked as " $\mathrm{A}$ " in Figure A3). This single activity element implicitly embeds both minigrant design (including the reversal of roles from grantee to grantor) and the distribution of funds for projects. In the model it contributes to four short-term outcomes, two of which, in the lower portion of Figure A3, are about increased individual capacity to produce garden and produce food and increase food production. The other two short-term outcomes represent critical shifts for individuals and the community. These are, respectively, "Food insecure community members feel that their experience and knowledge are valued" and "Softening lines between giver and receiver." Both of these are 
Journal of Agriculture, Food Systems, and Community D evelopment

visible as strategically critical outcomes in the overall model of FLV's work. Both of them have multiple arrows leading into them, reflecting their importance as goals of much of FLV's work, and multiple arrows leading out from them, signifying their strategic importance for achieving FLV's larger ultimate goals. As in the other models, design and management matter in ways that are distinct from the minigrant impacts from project funding.

\section{Whole Community Project}

Figure A4. Subsection of Whole Community Project (WCP)'s Collaborative Pathway Model Relating to Minigrants

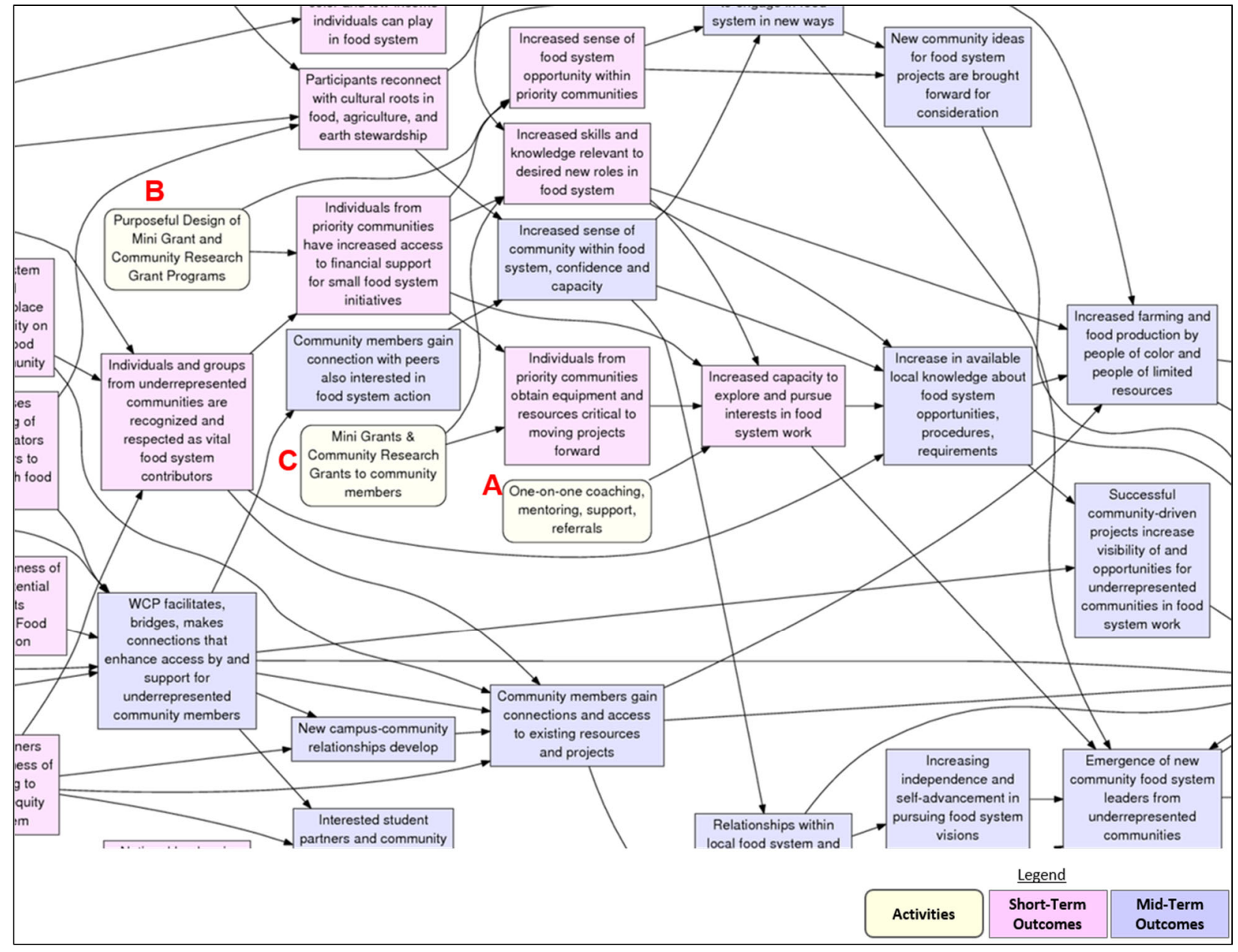

In the collaborative pathway model for WCP's work, individual, relationship-based support is reflected explicitly in one of the two minigrant design-related activities. The first, "O ne-on-one coaching, mentoring, support, referrals" (marked "A" in Figure A4), contributes to the short-term outcome of "Increased capacity to explore and pursue interests in food system work," which contributes, in turn, to increased local knowledge about "food system opportunities, procedures, requirements" and to an important midterm outcome of "Emergence of new community food system leaders from underrepresented communities." The second minigrant design-related activity is "Purposeful design of mini grant and community research grant programs" (B), which contributes to two short-term outcomes of increased "access to financial support for food 
system initiatives" and increased "sense of food system opportunity" for priority communities (defined as "food insecure community members who have traditionally been underrepresented in food system work" [https:/ / www.fooddignity.org/ collaborative-pathway-models]). The funding of minigrant projects (" $\mathrm{C}$ " in Figure A4) is presented as contributing to short-term outcomes of having the skills, knowledge, equipment, and resources necessary for food system projects and roles. All these paths were important in WCP's overarching and long-term goals of increasing the involvement of underrepresented community members in the food system through increased access to resources, entrepreneurship, employment, voice, and power in the food system. 